\title{
Inhalt, Vol. 3, No. 4, 1980
}

\section{Contents}

Impressum 155

Kraus-Sandmair, B. und Dinges, H. P., Wien

Untersuchungen zur Problematik einer jatrogenen Induktion von Mehrfachmalignomen anhand eines größeren Autopsiegutes 157

Husemann, B.; Neubauer, M. G. und Duhme, C, Erlangen

Sitzende Tätigkeit und Rektum-Sigma-Karzinom .... 168

Ries, P. und Reichert, P., Hannover

Ein Beitrag zur allgemeinen und speziellen Pathologie

der benignen odontogenen Tumoren 172

Bauer, H. W., München

Das schwangerschaftsassoziierte ou-Glykoprotein

((X2PAG). - Ein möglicher Marker zur Tumorverlaufs-

kontrolle? 183

Kokron, O.; Olbert, F. und Schlegl, A., Wien

Intraarterielle Infusionsbehandlung von Lungentumoren 187

Schalhorn, A.; Wilmanns, W. und Stupp-Poutot, G.,

München

Methotrexat-Nachweis im menschlichen Serum - Vergleich zwischen einer enzymatischen und einer enzymimmunologischen Methode 193

Buchbesprechungen 197

Onkologie-Mitteilungen 198

Imprint 155

Kraus-Sandmair, B. and Dinges, H. P., Wien

Jatrogenic induction of multiple malignancies - review of

a major post mortem material 157

Husemann, B.; Neubauer, M. G. and Duhme, C,

Erlangen

Sedentary occupation and rectal-sigmoid-cancer 168

Ries, P. and Reichart, P., Hannover

Contribution to General and Special Pathology of Benign

Odontogenic Tumours

172

Bauer, H. W., München

Pregnancy ass. $\alpha 2$-Glycoprotein - a possible Marker for

Tumourmonitoring? 183 
Kokron, O.; Olbert, F. and Schlegl, A., Wien

Intraarterial Infusionstherapy of Lung Tumours

Schalhorn, A.; Wilmanns, W. and Stupp-Poutot, G.,

München

Enzymatic Assay and Enzyme Immunoassay for Metho-

trexate - Comparison of two different methods

193

Book Reviews 197

Oncology Communications 198

Bibliographischer Hinweis: Inhaltsverzeichnisse dieser Zeitschrift erscheinen regelmäßig in current contents ${ }^{\circledR}$ sowie in anderen bibliographischen Diensten. 154

Hinweise für Autoren

Bitte senden Sie İhr Manuskript direkt an den Verlag S. Karger.

Es werden nur Originalarbeiten in deutscher Sprache veröffentlicht.

Das Manuskript soil in druckreifem .Zustand in dreifacher Ausferti-

gung eingereicht werden. Die Entscheidung über die Aufnahme erfolgt

aufgrund mehrerer Gutachten. Eine Kopie des Manuskripts soil grund-

sätzlich beim Autor verbleiben.

Die typographische Gestaltung und redaktionelle Bearbeitung ist dem

Verlag vorbehalten.

Der Verlag erwirbl alle Rechte an Sonder- und Abdrucken in anderen

Publikationen. Autorkorrekturen über 10\% der Satzkosten hat der

Autor zu tragen. Dem Autor stehen 40 Gratissonderdrucke seiner

Arbeit zu.

Markennamen müssen, wenn sie geschützt sind, mit einem hochge-stellten ${ }^{\circledR}$ bezeichnet werden.

Die Verantwortung für die korrekte Befolgung dieser Vorschrift liegt ausschließlich beim Autor.

Abkürzungen sollen möglichst sparsam verwendet werden. Bei spe-ziellen Abkürzungen sollte der Autor jeweils beim ersten Auftreten das Wort ausschreiben und die später verwendete

Abkürzung in Klam-mern folgen lassen: z.B. Adenosin-monophosphat (AMP).

Institutsangabe in der Sprache der Arbeit.

Zusammenfassungen sollen 20 Schreibmaschinenzeilen nicht über-schreiten. Eine Fassung in englischer Sprache und der englische Titel der Arbeit müssen mitgeliefert werden, auch wenn die Arbeit in deutscher Sprache abgefaßt ist. In die Zusammenfassung gehören keine Literaturzitate, Tabellen, Abbildungen und Abbildungshinweise sowie allgemein gehaltene Aussagen.

Schlüsselwörter sollen ebenfalls in deutscher und englischer Sprache abgefaßt werden. Zu einer Arbeit gehören drei bis fünf Key Words.

Tabellen, Abbildungen und Literaturzitate müssen im Text erwähnt werden.

Abbildungsvorlagen dürfen nicht aufgeklebt, gelocht oder mit Büro-klammern angeheftet eingereicht werden und sollen auf der Rückseite den Namen des Autors, den Titel des Beitrags sowie die Bildnummer tragen.

Adresse des Autors ist am Schluß der Arbeit vollständig anzugeben.

Literaturverzeichnis. Es soil nur die im Text zitierten Publikationen, diese dafür lückenlos, enthalten. Die Literatur ist entweder alpha-betisch zu ordnen oder entsprechend der Reihenfolge im Text zu numerieren.

Tagung der Deutschen Gesellschaft für Hämatologie und Onkologîe 
Der diesjährige Kongreß dieser Gesellschaft wird vom 5.-8. Oktober 1980 in Homburg/Saar abgehalten.

Hauptthemen des Kongresses sind: Behandlung bösartiger Blutkrankheiten - Monozyten und Makrophagen - Tumor-metastasierung.

Leitung und Auskunft: Prof. Dr. P. G. Scheurlen, Dir. d. I. Med. Univ.-Klinik, 6650

Homburg/Saar.

Ausschreibung des Gerhard-Domagk-Preises

Der Gerhard-Domagk-Preis für klinische oder experimentelle Krebsforschung wird hiermit ausgeschrieben. Einsendeschluß für die Arbeiten ist der 31. Dezember 1980.

Ein Merkblatt mit den genauen Bedingungen des Kuratoriums der Stiftung Krebsforschung Prof.

Dr. Gerhard Domagk, Münster, kann bei Priv. Doz. Dr. med. S. Ritter, Medizinische Univ.Klinik, Westring 3 in 4400 Münster angefordert werden. 